\title{
SymbioGBR: a web-based database of Symbiodinium associated with cnidarian hosts on the Great Barrier Reef
}

\author{
Linda Tonk ${ }^{1,2^{*}{ }^{+}}$, Pim Bongaerts ${ }^{2,3 \dagger}$, Eugenia M Sampayo ${ }^{1,2}$ and Ove Hoegh-Guldberg ${ }^{2,3}$
}

\begin{abstract}
Background: The algal endosymbionts (genus Symbiodinium) associated with scleractinian corals (and other reef invertebrates) have received a lot of research attention in the past decade, particularly as certain host-symbiont associations appear more affected by increasing seawater temperatures than others. With the rapid accumulation of information on the diversity of Symbiodinium, it is becoming increasingly difficult to compare newly acquired Symbiodinium data with existing data to detect patterns of host-symbiont specificity on broader spatial scales. The lack of a general consensus on the classification of Symbiodinium species coupled with the variety of different markers used to identify the genus Symbiodinium (ITS1, ITS2, LSU D1/D2, chloroplast 23S rDNA and psbA minicircle) further complicate direct comparison.

Description: The SymbioGBR database compiles all currently available Symbiodinium sequences and associated host information of data collected from the Great Barrier Reef into a single relational database that is accessible via a user-friendly, searchable web-based application (http://www.SymbioGBR.org). SymbioGBR allows users to query Symbiodinium types or sequences sourced from various genetic markers (e.g. ITS1, ITS2, LSU D1/D2 and chloroplast 23S) and invertebrate host species to explore their reported associations. In addition, as the database includes sequence information of multiple genetic markers, it allows cross-referencing between conventional (e.g. ITS2 region) and novel markers that exhibit low intragenomic variability (e.g. psbA region). Finally, the database is based on the collection details of individual specimens. Such host-symbiont associations can be assessed quantitatively and viewed in relation to their environmental and geographic context.

Conclusions: The SymbioGBR database provides a comprehensive overview of Symbiodinium diversity and hostassociations on the Great Barrier Reef. It provides a quick, user-friendly means to compare newly acquired data on Symbiodinium (e.g. raw sequences or characterized Symbiodinium types) with previous data on the diversity of invertebrate host-symbiont associations on the GBR. The inclusion of $p s b A^{\text {ncr }}$ sequence information allows for validation of widely used ITS1/ITS2 markers and their ability to accurately identify relevant sequences. Most importantly, centralization of sequence information from multiple genetic markers will aid the classification of Symbiodinium species diversity and allow researchers to easily compare patterns of host-Symbiodinium associations.
\end{abstract}

Keywords: Symbiodinium, Great Barrier Reef, Coral host, Symbioses, Biogeography

\footnotetext{
* Correspondence: I.tonk@uq.edu.au

${ }^{\dagger}$ Equal contributors

'School of Biological Sciences, The University of Queensland, St Lucia, QLD

4072, Australia

${ }^{2}$ ARC Centre of Excellence for Coral Reef Studies, The University of

Queensland, St Lucia, QLD 4072, Australia

Full list of author information is available at the end of the article
} 


\section{Background}

Symbiotic unicellular dinoflagellates of the genus Symbiodinium are best known for their association with scleractinian corals. The symbionts are essential to the functioning of the holobiont by providing their hosts with an important part of their energetic demands [1]. A wide range of reef-dwelling organisms, including the orders Scleractinia, Alcyonacea, Actinaria, Hydroida, Milleporina, Stolonifera, Veneroida, Zoanthidae, Corallimorpharia and Foraminiferida [2-4], depend on their endosymbionts for sufficient energy uptake in oligotrophic tropical seas.

The genus Symbiodinium consists of nine broad genetic clades, A-I [5], that were first revealed with small subunit (SSU) rDNA markers [6]. The more variable internal transcribed spacer unit (ITS) 1 and 2 revealed various genetically and ecologically distinct Symbiodinium types within these clades: e.g. C1, C3, C21 etc. [3,7-13]. Because of the multi-copy nature and the high intragenomic variance of the ribosomal DNA region, Symbiodinium types can contain co-dominant repeats in their genome that manifest as additional bands in the fingerprint pattern and are referred to as intragenomic variants: e.g. $\mathrm{C} 1 \mathrm{a}, \mathrm{C} 1 \mathrm{~b}, \mathrm{C} 1 \mathrm{c}$ etc. [2]. While inter-clade differences are substantial and comparable to order-level differences in non-symbiotic dinoflagellate groups [14], genetic distances within Symbiodinium clades are generally small. Despite this, closely related Symbiodinium types often relate to distinct ecological diversification and influence functional characteristics such as photosynthetic efficiency, growth or thermal tolerance of the host $[7,15,16]$.

The importance of Symbiodinium for the holobionts' (host plus symbionts) stress response is illustrated by the difference in vulnerability to increasing sea surface temperatures (SST) of same host, different symbiont combinations $[15,17,18]$. While many factors threaten the persistence of coral reefs, increasing SST is regarded as a primary threat to coral reefs by causing disruption of the symbiosis (coral bleaching) and leading to substantial mortality of reef invertebrates over the last two decades $[19,20]$. The identification of physiological differences in thermal tolerance and bleaching susceptibility between Symbiodinium types at the 'type' level $[17,18]$ combined with rising SST's underline the importance of understanding Symbiodinium diversity and this has spurred a broad research interest over the past decade [15,18,21-25].

In a recent meta-analysis of Symbiodinium data compiled from literature (Tonk et al. unpub. data), 62 different Symbiodinium types were identified from 207 host species on the Great Barrier Reef (GBR). Due to its many environmentally distinct areas and broad geographic range (spanning approximately $2300 \mathrm{~km}$ and including $10 \%$ of coral reefs worldwide) the GBR offers a unique opportunity to study patterns of Symbiodinium diversity. With continued efforts to define Symbiodinium communities an increasing number of novel types are described [26,27]. As information on cnidarian-Symbiodinium symbioses is steadily increasing and expanding its documented geographic extent, it becomes more difficult to compare new with existing Symbiodinium data. Although Symbiodinium sequences are readily available from generic genetic databases, their usefulness is impeded by the lack of a general consensus on the classification of Symbiodinium species. Coupled with the variety of different markers used to identify the genus Symbiodinium (internal transcribed spacer region (ITS) 1 and 2, large ribosomal subunit region (LSU) D1/D2, chloroplast 23S rDNA and psbA minicircle) it becomes more compelling to assimilate this vastly growing knowledge base into a single, searchable resource.

\section{Description}

We set out to compile currently available sequence and host-association data of Symbiodinium reported for the Great Barrier Reef (with the exception of experimentally treated and/or bleached host colonies) into a single relational database that is accessible as a web-based application (http://www.SymbioGBR.org). SymbioGBR allows users to query Symbiodinium types or sequences, and invertebrate host species to explore symbiotic associations. As the database is based on the collection details of individual specimens, such host-symbiont associations can be assessed quantitatively and viewed in relation to their environmental (e.g., depth) and geographic context (e.g., latitude).

Besides the work involved in compiling previous research, assimilating Symbiodinium sequence information has the added difficulty that different techniques (e.g. restriction fragment length polymorphism [RFLP], singlestranded conformation polymorphism [SSCP], denaturing gradient gel electrophoresis [DGGE], direct sequencing) and regions (e.g. 18 s rRNA, LSU D1/D2, ITS1/ITS2, chloroplast 23S) are used for identification. This complicates direct comparison unless the various DNA marker regions are used on a single sample [28]. Another problem arises when the different Symbiodinium sequences that are obtained using bacterially cloning of the rDNA are interpreted as if representing distinct Symbiodinium types [29]. Due to the multi-copy nature of the rDNA region ecologically relevant sequence variety is easily overestimated by such an approach and these results are likely to confound data generated by DGGE, SSCP, RFLP or direct sequencing $[28,30]$ and are therefor not included in the database.

The database includes sequence information sourced from multiple genetic markers (ITS1, ITS2, LSU D1/D2, chloroplast $23 \mathrm{~S}$ rDNA and the $p s b A$ minicircle $\left[p s b A^{n c r}\right]$ ) allowing the use of more regions to create stronger Symbiodinium phylogenies. The recent use of the noncoding region of the $p s b A^{n c r}$ was assessed to detect Symbiodinium diversity at high resolution [30] and has the advantage that, in contrast to the multi-copy markers 


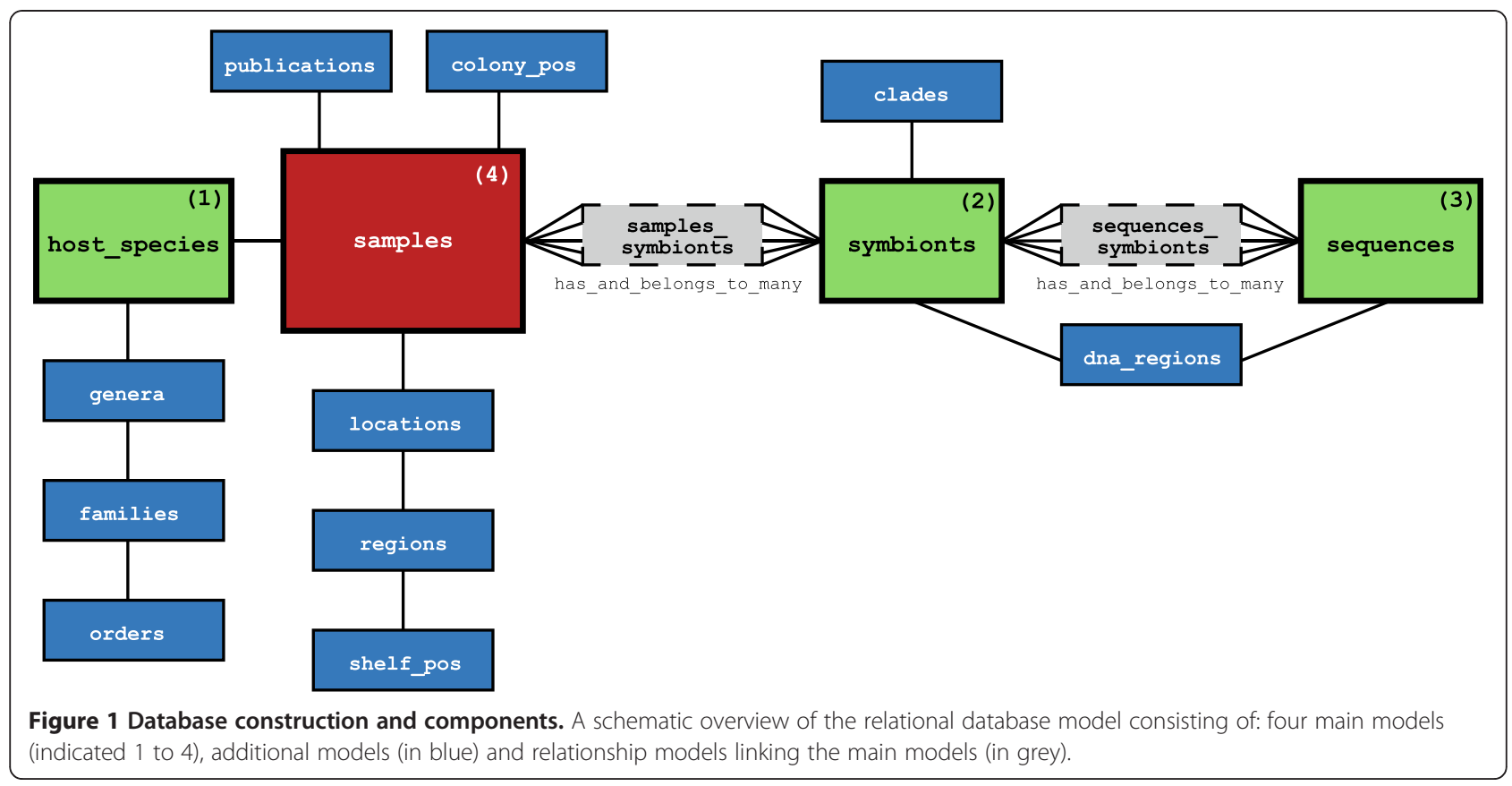

of the rDNA region, it's targeted region is relatively low in intragenomic variation, allowing validation of widely used ITS1/2 markers and their ability to accurately identify dominant sequences. Moreover the added resolution in combination with more conserved genetic markers has the potential to provide the resolution necessary to resolve Symbiodinium species classifications [30].

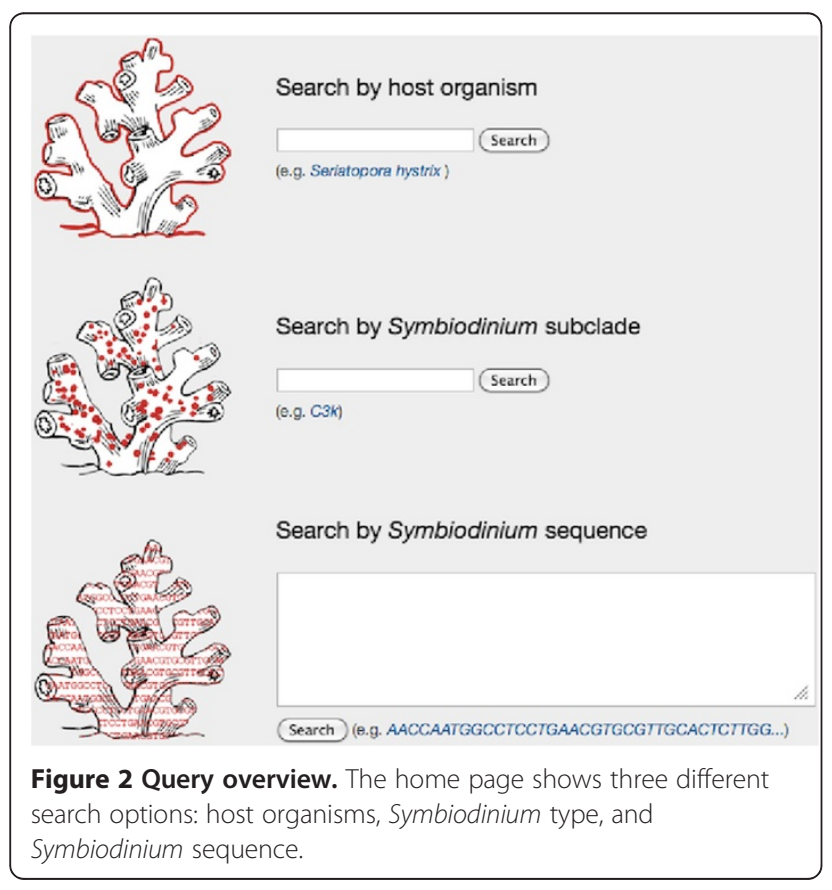

The database will be continuously updated building a unique and growing source of Symbiodinium sequence information across regions and cnidarian host-symbiont associations.

\section{Construction and content}

Data and website development

The SymbioGBR data was originally compiled in Microsoft Excel, but was then converted into a relational database model in PostgreSQL. Web interface and model associations were built using Ruby on Rails 3 and a range of Ruby Gems, and the web interface is currently hosted on the cloud platform Heroku. The relational database consists of four main models representing the different host species (1), Symbiodinium types (2) and sequences (3), which are connected through an extensive model that contains individual specimen records (4) (Figure 1). The remaining models provide additional standardized information about these data (e.g. source publications, sample location, etc.), in combination with contextual information included in each of the main models (Figure 1).

\section{Symbiodinium sequences and search option}

The database supports nomenclature based on both the ITS1 $[11,28,31,32]$ and ITS2 region $[2,8,28]$, but the open format of the database allows for any additional regions to be queried, such as LSU D1/D2, chloroplast $23 \mathrm{~S}$ rDNA or the $p s b A$ minicircle. The website contains a dynamically generated "cross-referencing" table (generated with data from samples that were typed using multiple markers), that can aid in comparing Symbiodinium 
diversity across different markers. Symbiodinium types that exhibit intragenomic variation that is detectable as additional bands (i.e. contain multiple ITS sequences) [28-30], can be queried through any of these sequences. When sequences are shared between multiple types (e.g., both C3a and C3b share the C3 sequence in their ribosomal genome), the user is offered the various additional sequence options to determine the exact type.

\section{Source data used in the current version}

At the time of publication, the SymbioGBR database contains a total of 65 Symbiodinium types (sensu LaJeunesse) and at least 219 invertebrate host species that are connected through 4,213 specimen samples. These data are based on 30 source publications, published in the period from 2001 to 2012 [2,4,8-11,17,18,28,30-50].

\section{Utility and discussion}

With the rapid accumulation of information on the diversity of Symbiodinium and the growing number of genetic tools, it is becoming increasingly difficult to compare newly acquired Symbiodinium data with existing data to detect patterns of host-symbiont specificity on broader spatial scales. This is further complicated by the fact that traditional sequence databases do not accommodate for a classification system with multiple sequences (i.e. representing intragenomic variants [28-30]) per "type" or include cloned sequence data [51]. The need for a web-based database that includes a comprehensive overview of different genetic markers is further illustrated by an increasing awareness that the resolution necessary to support Symbiodinium species classification indeed requires such a combination of genetic markers [28,30].

\section{Query interface}

SymbioGBR allows users to query Symbiodinium types (ITS1/ITS2) or sequences, and invertebrate host species to explore symbiotic associations on the GBR (Figure 2). The option to query host, symbiont type as well as Symbiodinium sequence is one of the main features that distinguish SymbioGBR from similar type websites [51]. When a host query is performed results are displayed in three sections respectively providing: 1) a summary of the results for that particular host species, 2) a list of the different symbiont types found in the queried host species, and 3) the locations the host species was sampled at per GBR section (Figure 3). Porites cylindrica is shown here as an example. The data output shows two Symbiodinium types (ITS2) found at ten different locations (Figure 3). When a Symbiodinium type query is

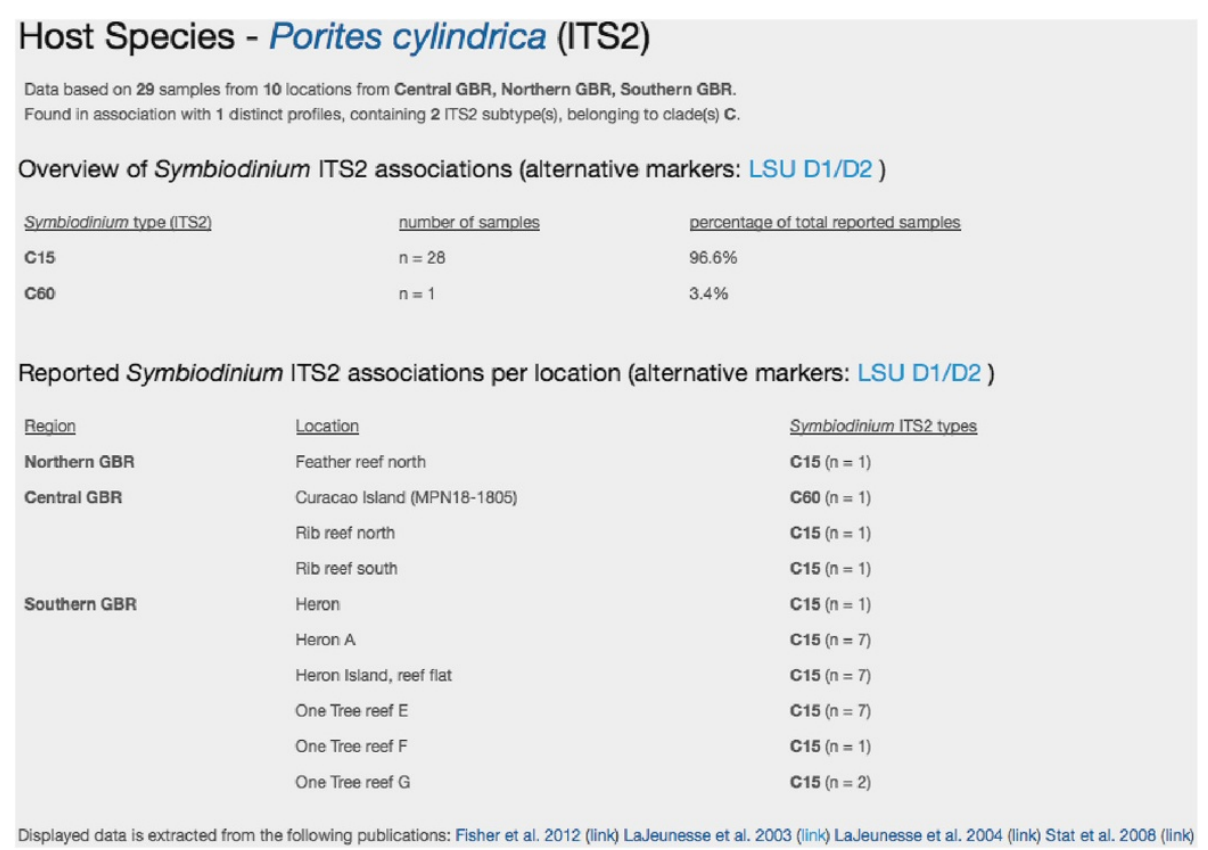

Figure 3 Host species query. After submitting Porites cylindrica as the search term, hit data are provided in three sections. First a summary is provided followed by an overall overview of the different Symbiodinium types harbored by $P$. cylindrica showing the number of host colonies sampled and the percentage of host colonies harboring that particular symbiont type. Finally the different locations are listed alphabetically per section of the GBR showing the Symbiodinium types and the number of host colonies sampled. The default setting shows ITS2 data but selecting the desired region in the top right corner can access different DNA regions. 
performed, it will show the different markers that information is available for. After selecting the marker of interest the results are displayed in three sections respectively providing: 1) a summary of the results for that particular symbiont type, 2) sequence information in fasta format with appropriate GenBank accession number, and 3) a list of the different host species in which the symbiont was found (Figure 4). Selecting from the listed host species shows the host species information as described above (Figure 3). For example, C3k data output shows this type is found in 17 host species, mostly from the genus Acropora (Figure 4). When a Symbiodinium sequence query is performed the matching sequence of the Symbiodinium type that particular sequence occurs in is displayed (Figure 5).

\section{Symbiont identification}

Different techniques were used to obtain Symbiodinium identity in the various studies that contributed to this database. While DGGE in combination with ITS1/ITS2 was the most commonly used method, other techniques such as RFLP and SSCP were used as well as a suite of different DNA regions (18S rRNA, D1/D2 LSU rDNA, chloroplast $23 \mathrm{~S} \mathrm{rDNA}$ and the $p s b A$ minicircle) generating variation in the resolution of differentiation, e.g. using the $18 \mathrm{~S}$ rRNA as a marker allows for

\begin{tabular}{|c|c|c|c|c|c|}
\hline \multicolumn{6}{|c|}{ Symbiont subclade - C3k (ITS2) } \\
\hline \multicolumn{6}{|c|}{ Symbiont subclade found in 37 samples, associated with 17 host species, from 6 locations from Central GBR, Northern GBR. } \\
\hline \multicolumn{6}{|l|}{ Sequence(s) } \\
\hline \multicolumn{6}{|c|}{ The symbiont subclade C3k contains 2 reported intragenomic variants (see available sequences below). } \\
\hline \multicolumn{6}{|l|}{ C3k (GenBank AY589737) } \\
\hline \multicolumn{6}{|c|}{ 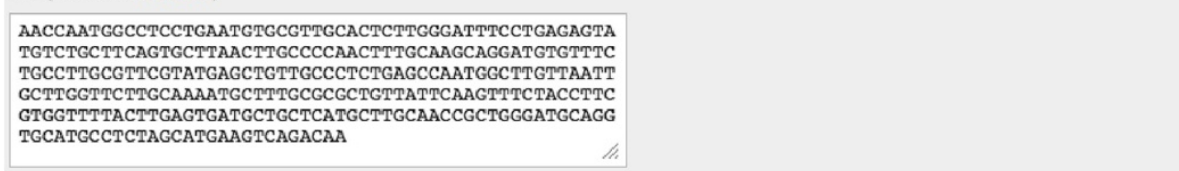 } \\
\hline \multicolumn{6}{|l|}{ C3 (GenBank AF499789) } \\
\hline \multicolumn{6}{|c|}{ 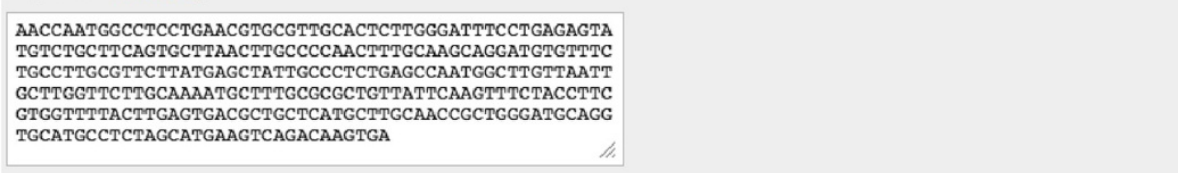 } \\
\hline \multicolumn{6}{|l|}{ Host associations } \\
\hline Species & $\%$ San & s with $\mathrm{C} 3 \mathrm{k}$ & Depth (inve & ed depth) & Other Symbiodinium found in this species \\
\hline Acropora cerealis & $17 \%$ & (total $n=6$ ) & $10-15 \mathrm{~m}$ & $(4-15 \mathrm{~m})$ & $\mathrm{C} 1, \mathrm{C} 3, \mathrm{C} 3 \mathrm{i}$ \\
\hline Acropora cytherea & $33 \%$ & (total $n=3$ ) & $4-5 \mathrm{~m}$ & $(4-5 m)$ & $\mathrm{C}_{3}$ \\
\hline Acropora digitifera & $25 \%$ & (total $n=4$ ) & $4-5 m$ & $(1-5 m)$ & $\mathrm{C} 3, \mathrm{C} 3 \mathrm{i}$ \\
\hline Acropora divaricata & $100 \%$ & (total $n=1$ ) & $10-15 \mathrm{~m}$ & $(10-15 \mathrm{~m})$ & \\
\hline Acropora florida & $50 \%$ & (total $n=4$ ) & $3.5 \mathrm{~m}$ & $(3-7 m)$ & $\mathrm{C} 3 \mathrm{i}$ \\
\hline Acropora grandis & $50 \%$ & (total $n=2$ ) & $5-7 \mathrm{~m}$ & $(5-7 \mathrm{~m})$ & $\mathrm{C3}$ \\
\hline Acropora humilis & $40 \%$ & (total $n=5$ ) & $3-4 m$ & $(3-4 m)$ & $\mathrm{C} 3, \mathrm{C} 3 \mathrm{i}$ \\
\hline Acropora hyacinthus & $33 \%$ & (total $n=3$ ) & $3-4 m$ & $(1-10 \mathrm{~m})$ & $\mathrm{C} 3$ \\
\hline Acropora millepora & $8 \%$ & (total $n=24$ ) & $4-15 m$ & $(0-15 \mathrm{~m})$ & C3, C3*_Fisher \\
\hline Acropora monticulosa & $50 \%$ & (total $n=2$ ) & $4-5 m$ & $(4-5 m)$ & $\mathrm{C} 3$ \\
\hline Acropora nasuta & $43 \%$ & (total $n=7$ ) & $3-15 m$ & $(1-15 \mathrm{~m})$ & $\mathrm{C} 3, \mathrm{C} 3 \mathrm{i}$ \\
\hline Acropora nobilis & $29 \%$ & (total $n=7$ ) & $4-15 m$ & $(3-15 \mathrm{~m})$ & $\mathrm{C} 1$ \& D1, C3, C3i \\
\hline Acropora palifera & $5 \%$ & (total $n=19$ ) & $5-7 \mathrm{~m}$ & $(0-15 \mathrm{~m})$ & $C 3, C 3 \& D 1, D 1$ \\
\hline Echinophyllia aspera & $58 \%$ & (total $n=12$ ) & $54-62 m$ & $(3-62 m)$ & C21, C3h, C3ha \\
\hline Funga cf. danai & $67 \%$ & (total $n=3$ ) & $54-55 m$ & $(54-55 \mathrm{~m})$ & $\mathrm{C} 3 \mathrm{i}$ \\
\hline Pachyseris speciosa & $80 \%$ & (total $n=10$ ) & $54-62 m$ & $(10-62 \mathrm{~m})$ & $\mathrm{C} 21, \mathrm{C} 3 \mathrm{~h}$ \\
\hline Pavona sp. & $50 \%$ & (total $n=2$ ) & $49-59 \mathrm{~m}$ & $(49-59 \mathrm{~m})$ & C3 \\
\hline
\end{tabular}

Figure 4 Symbiodinium type query. After submitting C3k as the search term hit a summary is provided followed by sequence information of C3 and C3k in fasta format. Additionally hit data include a table listing the different host species C3k was found in, the percentage and number of colonies with C3k, the investigated depth and other Symbiodinium types found in the host. 
comparison at Symbiodinium 'clade' level whereas ITS markers provide higher resolution and allow for comparative analyses at the Symbiodinium 'type' level [28]. The website provides an overview of the available sequence information of these various markers used for Symbiodinium identification (see Additional file 1) as well as a cross-referencing functionality. The dataset is dominated by 'type-level' Symbiodinium information using the ITS2 nomenclature sensu LaJeunesse, and ITS1 types sensu van Oppen. The nomenclature of ITS1 and ITS2 may differ (for example ITS1 type C1 equals ITS2 type C1, ITS1 type C2 refers to ITS2 type C3) and a cross-reference table is provided (see Table 1).

\section{Database content summary}

Host colonies sampled across the different sections of the GBR harboured Symbiodinium types from five different clades (clade A, B, C, D, and G). Most host colonies (92\%) contained clade C Symbiodinium (56 types) which were found in both octocorals and hard corals. Less than $2 \%$ of the hosts contained clade D types (D1, D1-4 (formerly known as D1a now assigned a provisional species name, Symbiodinium trenchi [22]) and D3) which appear predominantly in hard corals. An additional $5 \%$ of the host colonies contained a combination of clade $\mathrm{C}$ and $\mathrm{D}$ Symbiodinium types. Clades A, B, and G were rarely found (1.5\%). Clade A was found in fire corals (A7 in Millepora spp.) as well as several acroporids (Acropora longicyathus, A. millepora and A. valida). Clade B Symbiodinium was restricted to octocorals (B1 and B36 in Nephthea spp.) and clade $\mathrm{G}$ to octocorals and sponges (but found in a
Stylophora pistillata colony [50]). Most Symbiodinium types $(75 \%)$ were host specific to either one host species or to several species from the same genus (e.g. C120 in Seriatopora hystrix or $\mathrm{C} 17$ in the genus Montipora). Host generalist types such as C1, C3, C3h and C21 (25\% of the Symbiodinium types) were found in multiple host genera. The increased resolution portrayed by fine-scale genetic markers, such as the $p s b A$ minicircle, may reveal that certain host generalist Symbiodinium ITS-types in fact represent various host specialist sharing a common lineage at 'type-level'.

\section{Limitations \& future directions}

In order to maintain quality standards and avoid doublenaming of new sequences SymbioGBR will not provide the option to individually upload information to the web-based database. However, our aim is to keep the database updated with every peer-reviewed publication on Symbiodinium diversity on the GBR and we hope that other scientists will assist with contributions to guarantee provision of the most comprehensive and current overview of host-Symbiodinium associations on the GBR.

The database is currently dominated by ITS sequence information but has the application in place to provide comparative sequence data of multiple markers used for Symbiodinium identification (e.g. LSU D1/D2, chloroplast $23 \mathrm{~S}$ rDNA and $p s b A$ minicircle). The accumulation of different markers and their centralization in this database will provide the opportunity to cross-reference between DNA regions (including regions that vary in intragenomic

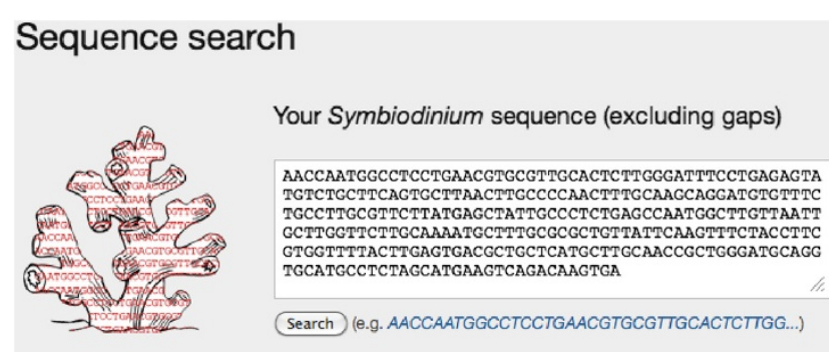

\section{Matching sequences}

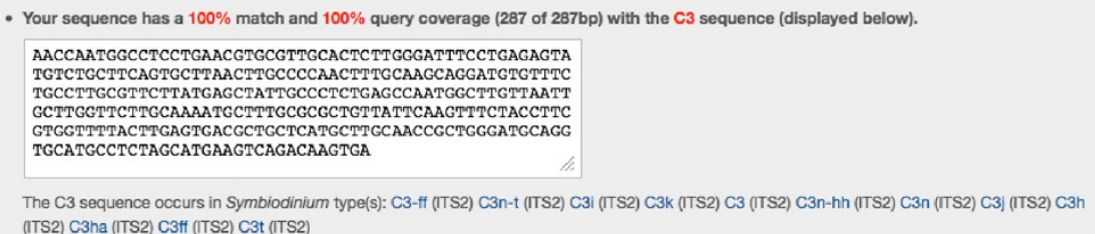

Figure 5 Symbiodinium sequence query. When submitting the C3k sequence in fasta format (excluding gaps) both the submitted Symbiodinium type C3k and the matching sequence are displayed as hit data as well as the percentage of matching base pairs and query coverage. 
Table 1 ITS1/ITS2 translation table

\begin{tabular}{|c|c|c|c|c|}
\hline ITS1 type & Genbank \# & ITS2 type & Genbank \# & Comments \\
\hline $\begin{array}{l}\text { C1_sensu } \\
\text { van Oppen }\end{array}$ & FJ529563 & $\mathrm{C} 1$ & AF333515 & \\
\hline$C 1: 1 a$ & & $C 1$ & AF333515 & $\begin{array}{l}\text { equals ITS1 Cla } \\
\text { and ITS2 } \mathrm{Cl}\end{array}$ \\
\hline C1:2 & AF380552 & $C 1$ & AF333515 & $\begin{array}{l}\text { equals ITS1 C2 and } \\
\text { ITS2 C1 }\end{array}$ \\
\hline$C 1: 3 a$ & AY758440 & C1 & AF333515 & $\begin{array}{l}\text { equals ITS1 C3a } \\
\text { and ITS2 } \mathrm{Cl}\end{array}$ \\
\hline $\mathrm{Cln}$ & & $\mathrm{C} 8 \mathrm{a}$ & FJ529613 & \\
\hline$C 2$ & AF380552 & C3 & AF499789 & sensu van Oppen \\
\hline C3 & AF380533 & C3 & AF499789 & sensu van Oppen \\
\hline $\mathrm{C} 3 a$ & AY758440 & Cl & AF333515 & \\
\hline C3t & FJ529569 & C3t & FJ529595 & \\
\hline C33 & FJ529566 & C33 & AY258498 & \\
\hline C33a & FJ529564 & C33a & EF541147 & \\
\hline C42a & FJ529561 & C42a & FJ529656 & \\
\hline C78a & FJ529562 & C78a & FJ529605 & \\
\hline C79 & FJ529560 & C79 & FJ529570 & \\
\hline$C d o t$ & AF180127 & C15 & AY239369 & \\
\hline Cdot & AF180127 & $\mathrm{C} 17$ & AY239369 & \\
\hline $\mathrm{Cn}$ & AY758555 & & & $\begin{array}{l}\text { no ITS2 match } \\
\text { sensu van Oppen }\end{array}$ \\
\hline
\end{tabular}

Example of the cross-referencing functionality of the website, showing an overview of Symbiodinium types that have been identified by both ITS1 and ITS2. Genbank accession numbers are provided when available. Symbiodinium types that differ in their ITS1 versus ITS2 nomenclature are indicated in italics. Nomenclature is sensu LaJeunesse unless stated otherwise.

variability) and improve consensus in naming. In addition the cross-reference function provides a means to maintain the applicability of previous work while molecular techniques are continuously evolving.

At this moment SymbioGBR is constricted to hostsymbiont information from localities within the GBR, one of the most densely studied areas worldwide in terms of Symbiodinium diversity. The GBR displays clade C Symbiodinium dominance with relatively small contributions of clade A, B, D and G Symbiodinium. Conversely, clade $C$ diversity in the GBR is much higher than the diversity found in other clades which is linked to adaptive radiation of clade $C$ in the Indo-Pacific [52]. The template for SymbioGBR was constructed in such a way making it suitable for upscaling to an Indo-Pacific or worldwide database if desired.

\section{Conclusions}

The SymbioGBR database provides a comprehensive overview of Symbiodinium diversity and host-associations on the Great Barrier Reef. As such, it provides a quick means to compare newly acquired data on Symbiodinium with previous patterns of diversity and invertebrate hostsymbiont specificity and places it in an ecological context. The inclusion of $p s b A^{n c r}$ sequence information allows for further validation of widely used ITS1/ITS2 markers and their ability to accurately identify dominant sequences. Moreover, sequence information sourced from multiple genetic markers allows the use of more regions to create stronger Symbiodinium phylogenies and this centralization of sequence information will aid Symbiodinium species classification.

\section{Availability and requirements}

The SymbioGBR is open to the public on the website http://www.SymbioGBR.org. No license is needed nor are there any restrictions for use by non-academics. The website is a web-application and platform independent.

\section{Additional file}

Additional file 1: Molecular marker overview.xls - Overview of the different symbiont types and the molecular markers used per type. Symbiodinium types are named sensu LaJeunesse unless stated otherwise. When Symbiodinium type level is unknown it is indicated as undefined. $X$ indicates the particular marker(s) used to identify the associated type.

\section{Authors' contributions}

LT compiled the information for the database, prepared the sequence alignments, helped to create the website front-end and drafted the manuscript. PB designed the data model, built the relational database application and drafted the manuscript. ES participated in the database compilation, the sequence alignment and helped to draft the manuscript. $\mathrm{OHG}$ helped to draft the manuscript. All authors have read and approved the final manuscript.

\section{Acknowledgements}

The authors thank Todd LaJeunesse (PSU) for feedback and for providing additional psbA sequence information and Madeleine van Oppen and Emily Howells (AIMS) for providing additional sample information. LT, PB, ES and $\mathrm{OHG}$ were supported by funding from the Great Barrier Reef foundation, the Queensland Smart State Fellowship Award (to OHG) and the ARC Centre Of Excellence for Coral Reef Studies.

\section{Author details}

${ }^{1}$ School of Biological Sciences, The University of Queensland, St Lucia, QLD 4072, Australia. ${ }^{2}$ ARC Centre of Excellence for Coral Reef Studies, The University of Queensland, St Lucia, QLD 4072, Australia. ${ }^{3}$ Global Change Institute, The University of Queensland, St Lucia, QLD 4072, Australia.

Received: 29 November 2012 Accepted: 5 March 2013

Published: 13 March 2013

\section{References}

1. Muscatine L, Porter JW: Reef corals: Mutualistic symbioses adapted to nutrient-poor environments. BioScience 1977, 27:454-460.

2. LaJeunesse TC, Loh WKW, van Woesik R, Hoegh-Guldberg O, Schmidt GW, Fitt WK: Low symbiont diversity in southern Great Barrier Reef corals, relative to those of the Caribbean. Limnol Oceanogr 2003, 48:2046-2054.

3. Pochon X, Garcia-Cuetos L, Baker AC, Castella E, Pawlowski J: One-year survey of a single Micronesian reef reveals extraordinarily rich diversity of Symbiodinium types in soritid foraminifera. Coral Reefs 2007, 26:867-882 
4. Van Oppen MJH, Mieog JC, Sanchez CA, Fabricius KE: Diversity of algal endosymbionts (zooxanthellae) in octocorals: the roles of geography and host relationships. Mol Ecol 2005, 14:2403-2417.

5. Pochon X, Gates RD: A new Symbiodinium clade (Dinophyceae) from soritid foraminifera in Hawai'i. Mol Phylogenet Evol 2010, 56:492-497.

6. Rowan R, Powers DA: A molecular genetic classification of zooxanthellae and the evolution of animal-algal symbioses. Science 1991, 251:1348-1351.

7. Iglesias-Prieto R, Beltran VH, LaJeunesse TC, Reyes-Bonilla H, Thome PE: Different algal symbionts explain the vertical distribution of dominant reef corals in the eastern Pacific. Proc R Soc B 2004, 271:1757-1763.

8. LaJeunesse TC, Bhagooli R, Hidaka M, DeVantier L, Done T, Schmidt GW, Fitt WK, Hoegh-Guldberg O: Closely related Symbiodinium spp. differ in relative dominance in coral reef host communities across environmental, latitudinal and biogeographic gradients. Mar Ecol Prog Ser 2004, 284:147-161.

9. LaJeunesse TC, Thornhill DJ, Cox EF, Stanton FG, Fitt WK, Schmidt GW: High diversity and host specificity observed among symbiotic dinoflagellates in reef coral communities from Hawaii. Coral Reefs 2004, 23:596-603.

10. Sampayo EM, Franceschinis L, Hoegh-Guldberg O, Dove S: Niche partitioning of closely related symbiotic dinoflagellates. Mol Ecol 2007 16:3721-3733.

11. van Oppen MJH, Palstra FP, Piquet AMT, Miller DJ: Patterns of coraldinoflagellate associations in Acropora: significance of local availability and physiology of Symbiodinium strains and host-symbiont selectivity. Proc R Soc B 2001, 268:1759-1767.

12. Frade PR, De Jongh F, Vermeulen F, Van Bleijswijk J, Bak RPM: Variation in symbiont distribution between closely related coral species over large depth ranges. $\mathrm{Mol}$ Ecol 2008, 17:691-703.

13. Warner ME, LaJeunesse TC, Robison JD, Thur RM: The ecological distribution and comparative photobiology of symbiotic dinoflagellates from reef corals in Belize: Potential implications for coral bleaching. Limnol Oceanogr 2006, 51:1887-1897.

14. Rowan R, Powers DA: Ribosomal-RNA sequences and the diversity of symbiotic dinoflagellates (zooxanthellae). Proc Natl Acad Sci USA 1992, 89:3639-3643.

15. Berkelmans R, van Oppen MJH: The role of zooxanthellae in the thermal tolerance of corals: a 'nugget of hope' for coral reefs in an era of climate change. Proc R Soc B 2006, 273:2305-2312.

16. Little AF, van Oppen MJH, Willis BL: Flexibility in algal endosymbioses shapes growth in reef corals. Science 2004, 304:1492-1494.

17. Jones AM, Berkelmans R, van Oppen MJH, Mieog JC, Sinclair W: A community change in the algal endosymbionts of a scleractinian coral following a natural bleaching event: field evidence of acclimatization. Proc R Soc B 2008, 275:1359-1365.

18. Sampayo EM, Ridgway T, Bongaerts P, Hoegh-Guldberg O: Bleaching susceptibility and mortality of corals are determined by fine-scale differences in symbiont type. Proc Natl Acad Sci USA 2008, 105:10444-10449.

19. Hughes TP, Baird AH, Bellwood DR, Card M, Connolly SR, Folke C, Grosberg R, Hoegh-Guldberg O, Jackson JBC, Kleypas J, et al: Climate change, human impacts, and the resilience of coral reefs. Science 2003, 301:929-933.

20. Pandolfi JM, Bradbury RH, Sala E, Hughes TP, Bjorndal KA, Cooke RG, McArdle D, McClenachan L, Newman MJH, Paredes G, et al: Global trajectories of the long-term decline of coral reef ecosystems. Science 2003, 301:955-958.

21. Baker AC, Starger CJ, McClanahan TR, Glynn PW: Coral reefs: Corals' adaptive response to climate change. Nature 2004, 430:741-741.

22. LaJeunesse TC, Pettay DT, Sampayo EM, Phongsuwan N, Brown B, Obura DO, Hoegh-Guldberg O, Fitt WK: Long-standing environmental conditions, geographic isolation and host-symbiont specificity influence the relative ecological dominance and genetic diversification of coral endosymbionts in the genus Symbiodinium. J Biogeogr 2010, 37:785-800.

23. Lien YT, Nakano Y, Plathong S, Fukami H, Wang JT, Chen CA: Occurrence of the putatively heat-tolerant Symbiodinium phylotype D in highlatitudinal outlying coral communities. Coral Reefs 2007, 26:35-44.

24. Oliver TA, Palumbi SR: Distributions of stress-resistant coral symbionts match environmental patterns at local but not regional scales. Mar Ecol Prog Ser 2009, 378:93-103.

25. Oliver TA, Palumbi SR: Do fluctuating temperature environments elevate coral thermal tolerance? Coral Reefs 2011, 30:429-440.
26. Silverstein RN, Correa AMS, LaJeunesse TC, Baker AC: Novel algal symbiont (Symbiodinium spp.) diversity in reef corals of Western Australia. Mar Ecol Prog Ser 2011, 422:63-75.

27. Wicks LC, Gardner JPA, Davy SK: Spatial patterns and regional affinities of coral communities at the Kermadec Islands Marine Reserve, New Zealand-a marginal high-latitude site. Mar Ecol Prog Ser 2010, 400:101-113.

28. Sampayo EM, Dove S, Lajeunesse TC: Cohesive molecular genetic data delineate species diversity in the dinoflagellate genus Symbiodinium. Mol Ecol 2009, 18:500-519.

29. Thornhill DJ, Lajeunesse TC, Santos SR: Measuring rDNA diversity in eukaryotic microbial systems: how intragenomic variation, pseudogenes, and PCR artifacts confound biodiversity estimates. Mol ECO/ 2007, 16:5326-5340.

30. LaJeunesse TC, Thornhill DJ: Improved resolution of reef-coral endosymbiont (Symbiodinium) species diversity, ecology, and evolutionary history through psbA non-coding region genotyping. PLOS One 2011, 6:e29013.

31. Goulet TL, LaJeunesse TC, Fabricius KE: Symbiont specificity and bleaching susceptibility among soft corals in the 1998 Great Barrier Reef mass coral bleaching event. Mar Biol 1998, 2008(154):795-804

32. Stat M, Loh WKW, Hoegh-Guldberg O, Carter DA: Symbiont acquisition strategy drives host-symbiont associations in the southern Great Barrier Reef. Coral Reefs 2008, 27:763-772.

33. Bongaerts P, Bridge TCL, Kline DI, Muir PR, Wallace CC, Hoegh-Guldberg O, Beaman RJ: Mesophotic coral ecosystems on the walls of Coral Sea atolls. Coral Reefs 2011, 30:335-335.

34. Bongaerts P, Riginos C, Hay KB, van Oppen MJH, Hoegh-Guldberg O, Dove $S$ : Adaptive divergence in a scleractinian coral: physiological adaptation of Seriatopora hystrix to shallow and deep reef habitats. BMC Evol Biol 2011, 11:303.

35. Bongaerts $P$, Riginos $C$, Ridgway $T$, Sampayo EM, van Oppen MJH, Englebert $N$, Vermeulen $F$, Hoegh-Guldberg $O$ : Genetic divergence across habitats in the widespread coral Seriatopora hystrix and Its associated Symbiodinium. PLoS One 2010, 5:e0871.

36. Fisher PL, Malme MK, Dove S: The effect of temperature stress on coralSymbiodinium associations containing distinct symbiont types. Coral Reefs 2012, 31:473-485.

37. Goulet TL, Simmons C, Goulet D: Worldwide biogeography of Symbiodinium in tropical octocorals. Mar Ecol Prog Ser 2008, 355:45-58.

38. Hill M, Allenby A, Ramsby B, Schoenberg C, Hill A: Symbiodinium diversity among host clionaid sponges from Caribbean and Pacific reefs: Evidence of heteroplasmy and putative host-specific symbiont lineages. Mol Phylogenet Evol 2011, 59:81-88.

39. Howells EJ, van Oppen MJH, Willis BL: High genetic differentiation and cross-shelf patterns of genetic diversity among Great Barrier Reef populations of Symbiodinium. Coral Reefs 2009, 28:215-225.

40. Jones A, Berkelmans R: Potential costs of acclimatization to a warmer climate: Growth of a reef coral with heat tolerant vs. sensitive symbiont types. PLoS One 2010, 5:e10437.

41. Loh WKW, Loi T, Carter D, Hoegh-Guldberg O: Genetic variability of the symbiotic dinoflagellates from the wide ranging coral species Seriatopora hystrix and Acropora longicyathus in the Indo-West Pacific. Mar Ecol Prog Ser 2001, 222:97-107.

42. Rodriguez-Lanetty M, Loh W, Carter D, Hoegh-Guldberg O: Latitudinal variability in symbiont specificity within the widespread scleractinian coral Plesiastrea versipora. Mar Biol 2001, 138:1175-1181.

43. Strychar KB, Coates M, Sammarco PW, Piva TJ, Scott PT: Loss of Symbiodinium from bleached soft corals Sarcophyton ehrenbergi, Sinularia sp and Xenia sp. J Exp Mar Biol Ecol 2005, 320:159-177.

44. Ulstrup KE, Berkelmans R, Ralph PJ, van Oppen MJH: Variation in bleaching sensitivity of two coral species across a latitudinal gradient on the Great Barrier Reef: the role of zooxanthellae. Mar Ecol Prog Ser 2006, 314:135-148.

45. Ulstrup KE, Hill R, van Oppen MJH, Larkum AWD, Ralph PJ: Seasonal variation in the photo-physiology of homogeneous and heterogeneous Symbiodinium consortia in two scleractinian corals. Mar Ecol Prog Ser 2008, 361:139-150.

46. Ulstrup KE, Kuehl M, van Oppen MJH, Cooper TF, Ralph PJ: Variation in photosynthesis and respiration in geographically distinct populations of two reef-building coral species. Aquat Biol 2011, 12:241-248. 
47. Ulstrup KE, Van Oppen MJH: Geographic and habitat partitioning of genetically distinct zooxanthellae (Symbiodinium) in Acropora corals on the Great Barrier Reef. Mol Ecol 2003, 12:3477-3484.

48. van Oppen MJH: Mode of zooxanthella transmission does not affect zooxanthella diversity in acroporid corals. Mar Biol 2004, 144:1-7.

49. van Oppen MJH, Bongaerts P, Underwood JN, Peplow LM, Cooper TF: The role of deep reefs in shallow reef recovery: an assessment of vertical connectivity in a brooding coral from west and east Australia. Mol Ecol 2011, 20:1647-1660.

50. van Oppen MJH, Mahiny AJ, Done TJ: Geographic distribution of zooxanthella types in three coral species on the Great Barrier Reef sampled after the 2002 bleaching event. Coral Reefs 2005, 24:482-487.

51. Franklin EC, Stat M, Pochon X, Putnam HM, Gates RD: GeoSymbio: a hybrid, cloud-based web application of global geospatial bioinformatics and ecoinformatics for Symbiodinium-host symbioses. Mol Ecol Resour 2011, 12:369-373.

52. LaJeunesse TC: "Species" radiations of symbiotic Dinoflagellates in the Atlantic and Indo-Pacific since the Miocene-Pliocene transition. Mol Biol Evol 2005, 22:570-581.

doi:10.1186/1472-6785-13-7

Cite this article as: Tonk et al: SymbioGBR: a web-based database of Symbiodinium associated with cnidarian hosts on the Great Barrier Reef. BMC Ecology 2013 13:7.

\section{Submit your next manuscript to BioMed Central and take full advantage of:}

- Convenient online submission

- Thorough peer review

- No space constraints or color figure charges

- Immediate publication on acceptance

- Inclusion in PubMed, CAS, Scopus and Google Scholar

- Research which is freely available for redistribution 